\title{
Impact of agricultural waste burning in the Shandong Peninsula on carbonaceous aerosols in the Bohai Rim, China
}

\author{
Xiaoping Wang ${ }^{\mathrm{a}, \mathrm{b}, \mathrm{c}}$, Yingjun Chen ${ }^{\mathrm{b}, *}$, Chongguo Tian ${ }^{\mathrm{b}}$, Guopei Huang ${ }^{\mathrm{b}}$, Yin Fang ${ }^{\mathrm{b}}$, Fan Zhang ${ }^{\mathrm{b}}$, Zheng Zong ${ }^{\mathrm{b}}$, \\ Jun Li ${ }^{\text {a }}$, Gan Zhang ${ }^{\mathrm{a}, * *}$ \\ a State Key Laboratory of Organic Geochemistry, Guangzhou Institute of Geochemistry, Chinese Academy of Sciences, Guangzhou 510640, China \\ ${ }^{\mathrm{b}}$ Key Laboratory of Coastal Environmental Processes and Ecological Remediation, Yantai Institute of Coastal Zone Research, Chinese Academy of Sciences, Yantai 264003, China \\ c Graduate University of Chinese Academy of Sciences, Beijing 100039, China
}

\section{H I G H L I G H T S}

- Collected $\mathrm{PM}_{25}$ samples at TI were analyzed for OC and EC.

- High winter EC concentrations were mainly from northwest source region.

- High spring OC levels were largely from biofuel burning in Shandong Peninsula.

- Agricultural field burning in the peninsula was a major source of summer OC and EC.

\section{A R T I C L E I N F O}

\section{Article history:}

Received 7 November 2013

Received in revised form 11 February 2014

Accepted 15 February 2014

Available online 4 March 2014

\section{Keywords:}

Organic carbon

Elemental carbon

Open crop residue burning

Tuoji Island

Bohai Rim

\begin{abstract}
A B S T R A C T
A total of $115 \mathrm{PM}_{2.5}$ samples were collected for analyzing organic carbon (OC) and elemental carbon (EC) at Tuoji Island (TI), China from November 2011 to December 2012. The results showed that annual arithmetical means of OC and EC concentrations were $3.8 \pm 2.7$ and $2.2 \pm 2.2 \mu \mathrm{g} \mathrm{m}^{-3}$, which contributed $8 \%$ and $4 \%$ of $\mathrm{PM}_{2.5}$ mass concentrations, respectively. High EC concentrations occurred in winter, contributed mainly by EC outflow from the northwest source region, while high OC concentrations were found during spring, attributed largely to biofuel burning in the Shandong Peninsula, and short distance and favorable transport from the peninsula to the TI. Agricultural waste open burning in the peninsula caused the largest variability of OC concentration in summer. Eliminating agricultural field burning in the peninsula can reduce at least one-third of concentration levels and half of northward transport fluxes of OC and EC in Bohai Rim in summer.
\end{abstract}

(c) 2014 Elsevier B.V. All rights reserved.

\section{Introduction}

Carbonaceous aerosols in fine particulate matter (particles with an aerodynamic diameter less than $2.5 \mu \mathrm{m}, \mathrm{PM}_{2.5}$ ) have received considerable attention because of their substantial link with global and regional climate change, visibility degradation, air quality, and public health (Anenberg et al., 2011; Ramanathan and Carmichael, 2008; Ramanathan et al., 2001). Carbonaceous aerosols are commonly classified as elemental carbon (EC) and organic carbon (OC). EC is a primary pollutant derived exclusively from the incomplete combustion from

\footnotetext{
* Correspondence to: Y. Chen, Yantai Institute of Coastal Zone Research, CAS, China. Tel.: + 865352109 020; fax: + 865352109000.

** Correspondence to: G. Zhang, Guangzhou Institute of Geochemistry, CAS, China. Tel.: + 86208529 0805; fax: + 862085290130 .

E-mail addresses: yjchen@yic.ac.cn (Y. Chen), zhanggan@gig.ac.cn (G. Zhang).
}

carbon-contained material, such as fossil fuel and biomass (Hu et al., 2012). OC can be mainly ascribed to primary organic carbon emitted from combustion and primary biogenic source, and secondary organic carbon formed through both photochemical oxidation of volatile precursors and subsequent gas-to-particle conversion processes (Fang et al., 2008). China has become one of the largest emitters of carbonaceous aerosols globally as a result of dramatic increases in large-scale farming, urbanization and industrial activities in recent years (Streets et al., 2004).

China is a large agricultural country, and agricultural waste burning is an important way of obtaining energy for cooking and heating in the countryside of the country (Cao et al., 2006). The burning of crop residues has been considered as an important source of carbonaceous species in China (Zhang et al., 2010). With increasing crop yields and the possibility of using other energy sources, open burning of agricultural waste has occurred more frequently in grain-producing regions in China although the government has enacted a series of regulations to 
prohibit field burning since the 1990s (Huang et al., 2012; Qin and Xie, 2012). It has been estimated that EC emission from agricultural field burning was 26 times in 2009 than in 1980 in China (Qin and Xie, 2012). The emissions get more serious in recent years and cause regional environmental pollution, which have attracted special concern in the two largest economic zones (Yangtze River Delta and Pearl River Delta) in China recently (Huang et al., 2011; Zhang et al., 2012). The highlight is vital to improve air quality because the emission from agricultural field burning is much easier to be controlled by government regulations than that from other sectors. However, little attention has been paid to the impact of open burning of crop residues on the regional levels of carbonaceous species in Bohai Rim region.

The Bohai Rim has become the third largest and most important economic zone after the Yangtze River Delta and the Pearl River Delta in China (Xin et al., 2011). It is located in northern China around the Bohai Sea and comprises Beijing and Tianjin municipalities as well as part of Hebei, Liaoning and Shandong provinces. Both international field campaigns and sampling campaigns carried out on remote islands showed that carbonaceous aerosols emitted from the Bohai Rim region could be detected in the downstream areas and coal burning was the main source of the continental outflow (Feng et al., 2007, 2012; Lim et al., 2003; Ma et al., 2012; Singh et al., 2009). However, extensive inventory studies showed that agricultural waste burning was a main emission source of carbonaceous aerosols in the region and open burning of crop residues in Shandong was the largest contributor of carbonaceous aerosols in the sector in China (Cao et al., 2006; Qin and Xie, 2011, 2012). The present study collected $\mathrm{PM}_{2.5}$ samples at Tuoji Island (TI) for analysis on carbonaceous aerosols. The major objectives are 1) to identify the temporal variation of OC and EC concentrations, 2) to assess factors causing significant temporal variation of $\mathrm{OC}$ and $\mathrm{EC}$ concentrations; and 3 ) to highlight the contribution of open burning of crop residues on concentration and transport flux of $\mathrm{OC}$ and EC in spring and summer in Bohai Rim area.

\section{Methodology}

\subsection{Sample collection}

The TI is located at the demarcation line between Bohai Sea and Yellow Sea as shown in Supporting information (SI), Fig. S1. It is $30 \mathrm{~km}$ north of the Shandong Peninsula with an area of $7.1 \mathrm{~km}^{2}$. No any industry is found and the islanders live by fishing. The sampling site $\left(38.19^{\circ} \mathrm{N}\right.$, $120.74^{\circ} \mathrm{E}$ ) is located on the sampling platform of a national station for background atmospheric monitoring at the northwestern tip of the TI (see SI Fig. S1). The sampling platform is about $10 \mathrm{~m}$ in height above the ground level. The residential area in the island lies about $3 \mathrm{~km}$ away in the northwest direction of the monitoring station. $\mathrm{PM}_{2.5}$ samples were collected every third day. It can be put off in turn in case of rain, snow, or strong wind. The sampling time started at 10:00 am LST and lasted for $24 \mathrm{~h}$. A total of 115 samples were collected on quartz fiber filters from 11 November 2011 to 25 December 2012 for the study (Whatman, QM-A, $20.3 \times 25.4 \mathrm{~cm}^{2}$, heated at $500^{\circ} \mathrm{C}$ for $8 \mathrm{~h}$ before use) using a Tisch high volume sampler at a flow rate of $1.13 \mathrm{~m}^{3} \mathrm{~min}^{-1}$.

\subsection{Sample analysis and $\mathrm{QA} / \mathrm{QC}$}

Quartz fiber filters were analyzed gravimetrically for $\mathrm{PM}_{2.5}$ mass concentrations using a Sartorius MC5 electronic microbalance with a $\pm 1 \mu \mathrm{g}$ sensitivity. After measurement of $\mathrm{PM}_{2.5}$ mass concentrations, carbonaceous components were analyzed by a Desert Research Institute (DRI) Model 2001 Carbon analyzer (Atmoslytic Inc., Calabasas, CA) following the Interagency Monitoring of Protected Visual Environment (IMPROVE) thermal/optical reflectance (TOR) protocol (Chow et al., 1993). Total OC is defined as the sum of the four OC fractions (OC1, $\mathrm{OC} 2, \mathrm{OC} 3$, and $\mathrm{OC} 4$ ) plus pyrolyzed organic carbon (POC), and total EC is defined as the sum of the three EC fractions (EC1, EC2, and EC3) minus POC. Quality assurance and control (QA/QC) procedures were also performed during the sample analysis. The details of the sample analysis are described in SI.

\subsection{Data analysis}

\subsubsection{Temporal trend analysis}

The Mann-Kendall (M-K) method was used to reveal the temporal trend of carbonaceous aerosols at the TI. The M-K method can be used to test a non-linear trend as well as to determine the timing of each abrupt change for the time variables. The method has been widely used as an effective method to evaluate the presence of a statistically significant trend in hydrological and climatological time series (Liu and Yang, 2010; Mohsin and Gough, 2010). The M-K test is applicable only when all the observations in a time series are serially independent. Therefore, lag-1 serial autocorrelation was examined before applying the M-K test (Yue et al., 2002). The detailed computing processes of the $\mathrm{M}-\mathrm{K}$ test were referred to previous studies (Mohsin and Gough, 2010; Yue et al., 2002) and shown in SI. The M-K test was performed using LF95 Version 5.7.

\subsubsection{Co-emission assessment}

Given that EC is known to exist in an inert state in the atmosphere, the correlation of OC to EC is often used to estimate typically their coemission in the atmosphere (Cao et al., 2007). In the present study, the assessment of OC and EC co-emission was determined by the Pearson correlation after natural logarithm transformation of their concentrations since they were log-normally distributed as illustrated later. A time moving correlation method was also performed to feature the temporal change of $\mathrm{OC}$ and EC co-emission. The moving correlation method can produce a time series of correlation coefficient. The ith correlation coefficient indicates the relationship between OC and EC concentrations from ith to $(i+m)$ th samples. In which, $m$ is the sample number from the time series of measured OC and EC concentrations. Here 6, 10 and 15 $\mathrm{OC}$ and EC concentration data from successive samples (equivalent to 18,30 and 45-days) were used to assess the temporal change of OC and EC co-emission. The moving correlation was performed using LF95 Version 5.7.

In addition, several statistical values of $\mathrm{OC}, \mathrm{EC}$ and $\mathrm{PM}_{2.5}$ concentrations were used to estimate their seasonal variation and distribution. They include minimum, maximum, geometric mean, arithmetic mean, coefficient of variation (CV), Kolmogorov-Smirnov (K-S) test and mean significant test. SPSS Version 17.0 was employed for the statistical analysis.

\subsection{Source identification}

Backward trajectories and fire counts were used to assess potential sources of observed carbonaceous aerosols in different air masses encountered during the sampling period. Backward trajectories were generated by the hybrid single-particle Lagrangian integrated trajectory (HYSPLIT) model, which is available on the National Oceanic and Atmospheric Administration Air Resource Laboratory website (www. arl.noaa.gov/ready/hysplit4.html) (Draxler and Rolph, 2003). 72-h backward trajectories were generated at four different starting times during the $24 \mathrm{~h}$ sampling period with $6 \mathrm{~h}$ time intervals. The trajectories were calculated for air masses starting from the sampling site at $10 \mathrm{~m}$ above ground level. Thus, 4 backward trajectories were generated for each sample. Fire counts were detected by MODIS (Moderate Resolution Imaging Spectroradiometer) on the NASA satellites and the integrated data are available at http://firms.modaps.eosdis.nasa.gov/firemap/ (Louis, 2013). One fire count in the map represents an active fire in a resolution of $1 \times 1 \mathrm{~km}$ pixel. 


\section{Results and discussion}

\subsection{Mass concentrations of carbonaceous aerosols and $P M_{2.5}$}

SI Fig. S2 presents OC, EC and $\mathrm{PM}_{2.5}$ concentrations at the TI for the entire sampling period. Table 1 lists the statistical values of OC, EC and $\mathrm{PM}_{2.5}$ concentrations. The K-S test was calculated by original data and the measurements after natural logarithm transformation. OC, EC and $\mathrm{PM}_{2.5}$ concentrations varied from 0.5 to 15 , from 0.2 to 14 and from 3.7 to $144 \mu \mathrm{g} \mathrm{m}^{-3}$ during the entire sampling period, respectively. On average, OC and EC concentrations accounted for $8 \%$ and $4 \%$ of $\mathrm{PM}_{2.5}$ mass concentration, respectively. The contributions were notably lower than that in Chinese cities (Cao et al., 2007). Both geometrical and arithmetical averages of OC concentrations were two times higher than that of EC, which were comparable with the ratio of OC to EC measured at Gosan ABC Superstation on Jeju Island, Korea during August 2007-September 2008 (Lim et al., 2012). The CV of EC concentrations was larger than that of $\mathrm{OC}$ and $\mathrm{PM}_{2.5}$ because of the large variability of EC concentrations during the early part of the sampling period (see SI Fig. S2). The K-S test showed that all concentrations were lognormally distributed for the entire sampling period, as shown as an example for OC in SI Fig. S3. Such a distribution indicates that low concentration levels dominated the entire sampling period. Those relative high concentrations were caused by episodic transport events carrying the

Table 1

Statistical values of original and natural logarithm transformed concentrations of OC, EC and $\mathrm{PM}_{2.5}\left(\mu \mathrm{g} / \mathrm{m}^{3}\right)$.

\begin{tabular}{|c|c|c|c|}
\hline & $\mathrm{OC}$ & $\mathrm{EC}$ & PM2.5 \\
\hline \multicolumn{4}{|c|}{ Total (Nnmber of samples $=115)$} \\
\hline Minimum & 0.49 & 0.17 & 3.69 \\
\hline Maximum & 14.74 & 13.55 & 144.22 \\
\hline Geometric mean & 3.07 & 1.32 & 42.04 \\
\hline Arithmetic mean & 3.85 & 1.94 & 53.22 \\
\hline $\mathrm{CV}$ & 0.69 & 1.05 & 0.67 \\
\hline K-S test & $9.50 \mathrm{E}-05$ & $3.64 \mathrm{E}-11$ & $5.76 \mathrm{E}-07$ \\
\hline $\mathrm{K}-\mathrm{S}$ test $(\ln )$ & 0.20 & 0.18 & 0.20 \\
\hline \multicolumn{4}{|c|}{ Winter (number of samples $=26$ ) } \\
\hline Minimum & 0.78 & 0.48 & 3.69 \\
\hline Maximum & 9.75 & 13.55 & 115.52 \\
\hline Geometric mean & 2.89 & 2.15 & 32.42 \\
\hline Arithmetic mean & 3.57 & 3.31 & 42.39 \\
\hline $\mathrm{CV}$ & 0.66 & 1.02 & 0.71 \\
\hline K-S test & 0.11 & $2.39 \mathrm{E}-04$ & 0.02 \\
\hline $\mathrm{K}-\mathrm{S}$ test $(\ln )$ & 0.20 & 0.20 & 0.20 \\
\hline \multicolumn{4}{|c|}{ Spring (number of samples $=28$ ) } \\
\hline Minimum & 2.06 & 0.72 & 33.56 \\
\hline Maximum & 9.10 & 3.56 & 144.22 \\
\hline Geometric mean & 4.61 & 1.69 & 72.47 \\
\hline Arithmetic mean & 5.03 & 1.89 & 80.23 \\
\hline $\mathrm{CV}$ & 0.40 & 0.46 & 0.44 \\
\hline K-S test & 0.20 & 0.06 & 0.13 \\
\hline $\mathrm{K}-\mathrm{S}$ test $(\ln )$ & 0.20 & 0.09 & 0.09 \\
\hline \multicolumn{4}{|c|}{ Summer (number of samples $=27$ ) } \\
\hline Minimum & 0.49 & 0.17 & 13.15 \\
\hline Maximum & 14.74 & 4.22 & 143.84 \\
\hline Geometric mean & 2.26 & 0.83 & 41.98 \\
\hline Arithmetic mean & 3.24 & 1.14 & 51.15 \\
\hline $\mathrm{CV}$ & 1.06 & 0.90 & 0.71 \\
\hline K-S test & $4.56 \mathrm{E}-06$ & $1.29 \mathrm{E}-05$ & $4.65 \mathrm{E}-05$ \\
\hline $\mathrm{K}-\mathrm{S}$ test $(\ln )$ & 0.11 & 0.20 & 0.12 \\
\hline \multicolumn{4}{|c|}{ Autumn (number of samples $=22$ ) } \\
\hline Minimum & 1.16 & 0.24 & 10.87 \\
\hline Maximum & 11.01 & 3.30 & 112.07 \\
\hline Geometric mean & 3.18 & 0.98 & 36.05 \\
\hline Arithmetic mean & 3.94 & 1.31 & 45.68 \\
\hline $\mathrm{CV}$ & 0.70 & 0.70 & 0.68 \\
\hline K-S test & $6.32 \mathrm{E}-03$ & 0.20 & 0.20 \\
\hline K-S test $(\ln )$ & 0.20 & 0.18 & 0.20 \\
\hline
\end{tabular}

CV: Coefficient of variation, K-S test: Kolmogorov-Smirnov test. pollutants from source regions under favorable atmospheric transport pathway. In addition, OC and EC concentrations at the TI were compared with that in surrounding areas. The details are shown in SI text, Fig. S4 and Table S1.

\subsection{Seasonal variation of carbonaceous species}

Table 1 also lists those statistical values of seasonal OC, EC and $\mathrm{PM}_{2.5}$ concentrations during winter (December, 2011-February 2012), spring (March-May 2012), summer (June-August 2012), and autumn (September-November 2012). In general, seasonal EC concentrations at the TI were a descending order of winter $>$ spring $>$ autumn $>$ summer, while the order was spring $>$ autumn $>$ winter $>$ summer for OC concentrations. The highest concentration in winter and the lowest one in summer have been considered to be a common feature of OC and EC concentrations in north China. High winter pollution levels are caused by a combination of the increased number of emission sources from commercial/residential combustion for space heating under unfavorable atmospheric dispersion conditions and possible thermal inversions (Cao et al., 2007; Feng et al., 2007). High winter EC concentrations at the TI were mainly attributed to EC outflow from the northwest source region carried by the East Asian winter monsoon (see winter backward trajectories in SI Fig. S5) as that reported at Changdao Island (Feng et al., 2007). The seasonal changes of OC concentrations at the TI were different from the common feature in north China, suggesting that there were unexpected source emissions and/or environmental condition to contribute high OC concentrations at the TI in spring.

Besides lognormal distribution of all seasonal OC and EC concentrations, the $\mathrm{K}-\mathrm{S}$ test also shows that winter and spring OC concentrations (see SI Fig. S6) and spring and autumn EC concentrations obeyed normal distributions. The normal distributions imply that winter and spring OC and spring and autumn EC in the atmosphere were supported by a relatively stable source emission and/or environmental condition. The aspect was also characterized by respectively smaller CV in the seasons (see Table 1). Higher concentration level and larger K-S test value for $\mathrm{OC}$ in spring than in winter indicate more intensive contribution during spring due to the increase of source emission and/or effectiveness of transport route from source regions.

The mean significant test shows that seasonal OC concentrations were significant differences between winter and spring, and spring and summer at a 99\% confidence level, whereas such a significant difference for seasonal EC levels was only spotted between spring and summer (see SI Table S2).

\subsection{Temporal trends and co-emission of carbonaceous species}

In order to further identify the temporal trend and significant change of OC and EC concentrations, the M-K test was performed. SI Table S3 lists the lag- 1 time serial autocorrelation and significant level of carbonaceous compounds during the sampling period. Since the time serials of OC concentrations were not a significant autocorrelation, the M-K test was applied to original data to examine its temporal trend. The time serial of EC concentrations was a significant autocorrelation at $0.1 \%$ significant level. The temporal trend of EC concentrations was examined by the $\mathrm{M}-\mathrm{K}$ test after removing the lag- 1 autocorrelation from the time series. Fig. 1 shows the sequential $\mathrm{M}-\mathrm{K}$ trend of the $\mathrm{OC}$ and EC concentrations for the entire sampling period, in which, both the statistics for the forward series, UF, and for the backward series, UB, are plotted against the time. For the OC time series, the abrupt changes began on November 22, 2011 (at the intersection) and its trend increased on January 13,2012 . The significant abrupt changes at a 95\% confidence interval level started from February 13 and continued until July 12,2012 . Thereafter, a downtrend was showed. EC concentrations exhibited a different trend compared with that of OC. The temporal trend of EC concentration sloped gently down. Its abrupt change started from April 15 and became significant after July 25, 2012. The M-K 


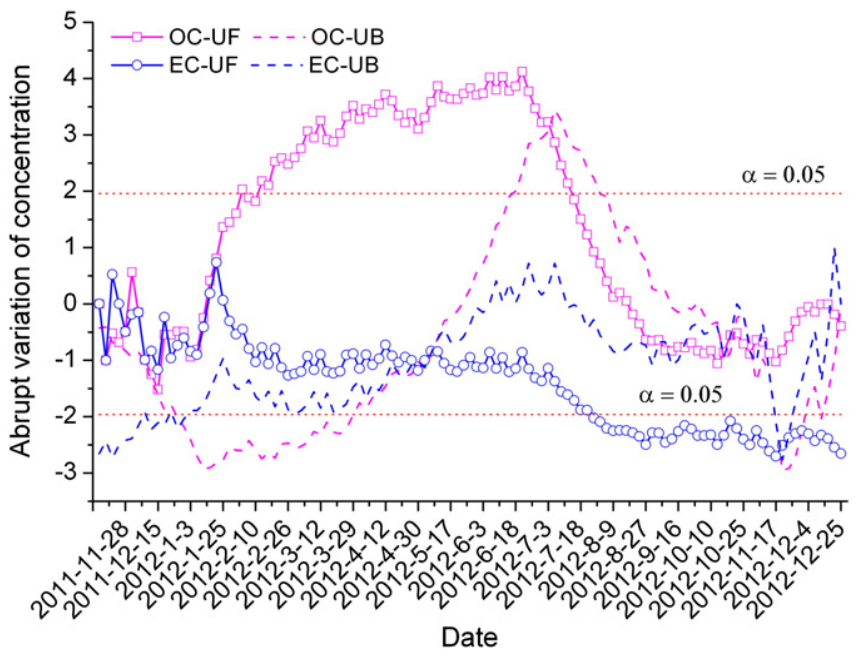

Fig. 1. Abrupt variations in $\mathrm{OC}$ and EC concentrations at Tuoji Island, China during November 15, 2011-December 25, 2012. The test statistics from sequential Mann-Kendall test for forward and backward time series are plotted to detect the abrupt changes. Two red dotted lines show the range of significant level at $5 \%$.

estimation establishes the start and duration of the significant changes of the OC and EC concentration time series after the mean significant test as aforementioned.

Considering the difference between $\mathrm{OC}$ and EC temporal trends, we correlated OC and EC time series to further confirm the time of their significant changes. Although significant correlation between OC and EC concentrations for the entire sampling period $(p=0.001)$ was found, the correlation coefficient $(r=0.34)$ was low compared with those reported in Chinese cities (Cao et al., 2007). The low correlation indicates obvious differences of source emission and/or environmental condition contributing OC and EC concentrations during the sampling period. Thus, a moving correlation was conducted for OC and EC time series. The moving correlations with 6,10 , and 15 OC and EC successive data are displayed in SI Fig. S7. The three correlations show a similar pattern that is the lowest correlation coefficient near the ending of January and the beginning of February and the second lowest value about the ending of July and the beginning of August. The two poor values indicate the obvious changes of OC and EC concentrations at the TI in February and August, which are in agreement with the starting times with significant abrupt changes of OC and EC concentrations (see Fig. 1).

\subsection{Impact of biofuel burning in winter and spring}

In order to explore potential factors linking with the change in $\mathrm{OC}$ and EC concentrations in February, we compared 72-h back trajectory cluster maps during the sampling days in December 2011, January and February 2012 (see SI Fig. S8). In general, all air masses in December 2011 and the next January were from north and northwest regions of the island, driven by East Asia winter monsoon (Jhun and Lee, 2004). Those air masses carried carbonaceous species from the similar emission source areas to the island, featured by a covariant pattern of both temporal trend and concentration change in OC and EC. Nevertheless, a distinct transport pathway in February (39\% of total air masses) passing through the Shandong Peninsula originating from the sea was found by comparing with air masses in January, 2012. Interestingly, the date (February 13) with the first air masses passing through the Shandong Peninsula was in agreement with the starting times of the significant increase in $\mathrm{OC}$ concentration. It suggests that the $\mathrm{M}-\mathrm{K}$ test is an effective tool to examine significant change in air pollutants. The significant increase in OC concentrations indicates not only a more efficient transport route from the Shandong Peninsula to the TI due to short distance (see SI Fig. S4) but also intensive OC emission in the peninsula.
Shandong was estimated as the largest emission source region of carbonaceous aerosols in northern China, and agricultural waste burning contributed to over $42 \%$ of total OC and $35 \%$ of total EC emissions in the province in 2005 (Cao et al., 2006; Zhao et al., 2012). It was reported that seasonal variations in the ratio of OC to EC emissions in northern China (including Shandong) were attributed largely to coal and biofuel combustion for heating and cooking in cold season, and agriculture field burning after the harvest period (Cao et al., 2006). Agricultural waste burning figured high factor of OC/EC ratio, suggesting high OC emission and low EC emission in the Shandong Peninsula in cold season and after the harvest period. This release may result in OC increase and EC decrease at the monitoring site since February.

The emission of carbonaceous species from biofuel burning for space heating reduces with increasing air temperature in spring, whereas, OC concentrations continually increased, suggesting occurrence of another emission source in the peninsula in spring. Fire counts in spring were denser than that in winter (see SI Fig. S9), which mainly represent agricultural field burning. This release can partly contribute to increasing $\mathrm{OC}$ and decreasing EC at the monitoring site in spring.

\subsection{Impact of agricultural field burning in summer}

The most intensive fire counts were in summer as shown in SI Fig. S9 and the maximum, minimum and the largest CV of OC concentrations occurred in the season (see Table 1). The event implies large variability in $\mathrm{OC}$ in summer, which attributed possibly to episodic intensive source emission and favorable transport route. Emission owing to agriculture field burning is highly variable with space and time, agreeing with large variability in $\mathrm{OC}$ in summer. In order to further identify the association between variations in $\mathrm{OC}$ concentrations and open burning events of agricultural waste during summer, we estimated the route of back trajectories of air mass and occurrence of accumulative fire counts during high and low concentrations of OC and EC.

Fig. 2 displays accumulative fire counts during June 4-6 and 72-h back trajectories of air mass at the TI on June 6, 2012. SI Fig. S10 illustrates accumulative fire counts during June 19-21 (a) and 72-h back trajectories of air mass at the TI on June 21 (b), 2012, respectively. On the two sampling days, peak OC concentrations were found. Those back trajectories of air mass passed through the Shandong Peninsula, where marked fire counts were presented. The OC concentration at the TI on June $6,2012\left(14.74 \mu \mathrm{g} \mathrm{m}^{-3}\right)$ was higher than that on June 21, $2012\left(12.02 \mu \mathrm{g} \mathrm{m}^{-3}\right)$, agreeing with denser fire counts in the Shandong Peninsula during June 4-6 (see Fig. 2) than that during June 19-21 (see SI Fig. S10). Correspondingly, the highest EC concentrations in summer also occurred on the two sampling days.

SI Fig. S11 shows 72-h back trajectories of air mass at the TI on July 7 , 10 and 19, 2012, when low OC and EC concentrations were found. Air masses on July 7 surrounded Bohai Sea, when OC and EC concentrations were the highest among the three periods. The second air mass passed through the Shandong Peninsula from southeastern clean sea, when the lowest OC $\left(0.49 \mu \mathrm{g} \mathrm{m}^{-3}\right)$ and EC $\left(0.17 \mu \mathrm{g} \mathrm{m}^{-3}\right)$ concentrations were presented. Meanwhile, as shown in SI Fig. S12, no accumulative fire counts were found during July 7-9, 2012 along the route of the back trajectories of air mass on the peninsula. It suggests that high $\mathrm{OC}$ and EC concentrations in summer at the TI were contributed largely by agricultural waste open burning in field in the Shandong Peninsula. Similarly, the reduction of open burning of crop wastes in the Shandong Peninsula caused mainly the decrease in OC and EC concentrations at the TI after July (see text and Figs. S13-14 in SI).

\subsection{Transport flux and contribution of agricultural waste open burning}

Since the results presented above have linked the OC and EC concentrations at the TI with agricultural residue open burning in field, it is worthwhile to extend the investigation to the transport flux and potential impact of open burning of agricultural residue in the Shandong 


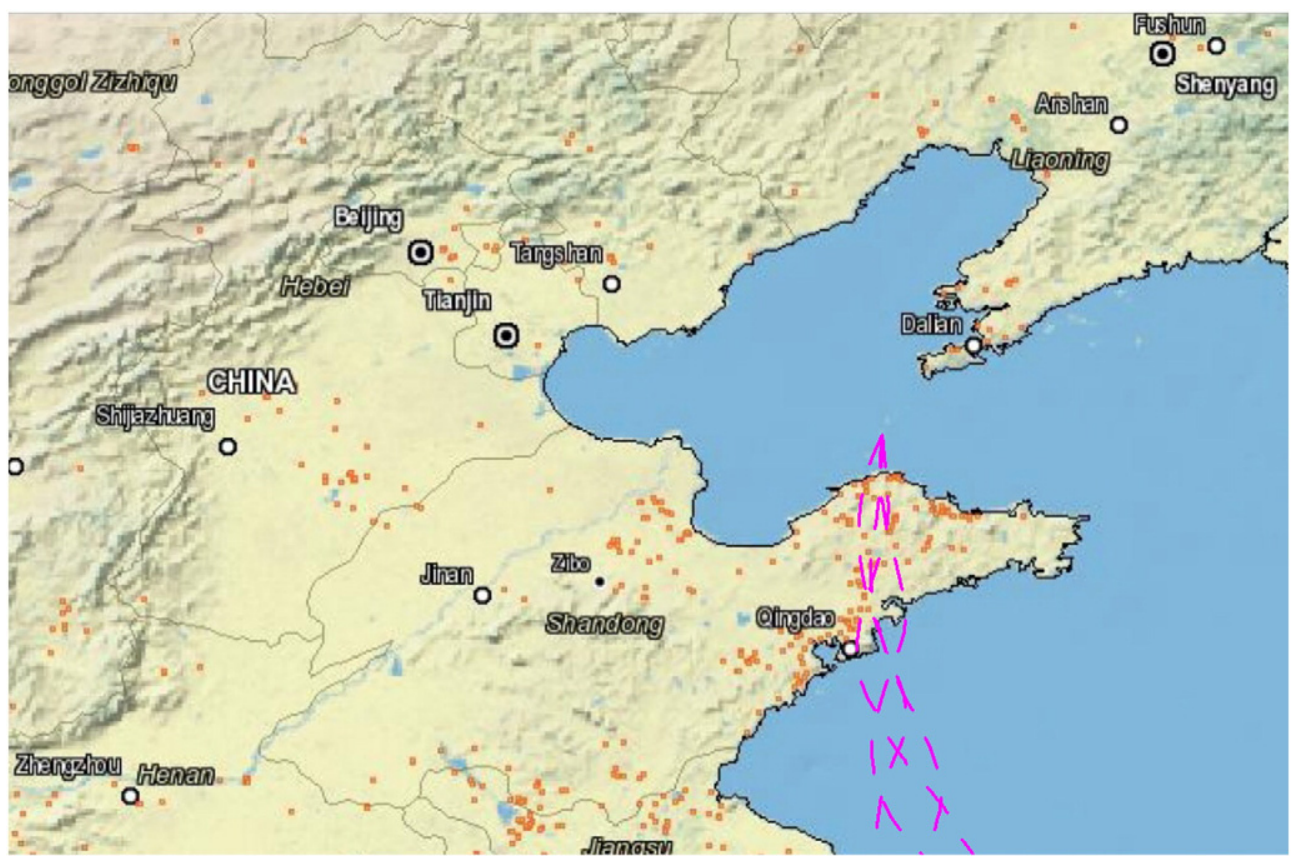

Fig. 2. Accumulative satellite fire count (orange points) diagram during June 4-6 and 72-h back trajectories (pink dashed lines) on June 6, 2012.

Peninsula on the transport flux. SI Fig. S15 and Fig. S16 illustrate annual and seasonal atmospheric transport fluxes of $\mathrm{OC}$ and EC concentrations, calculated as the sum of the daily $\mathrm{OC}$ and EC concentration fluxes $(=\mathrm{V} \times \mathrm{C}$, where $\mathrm{V}$ is the horizontal wind components and $\mathrm{C}$ is the air concentration), respectively. The annual transport fluxes were $647 \mathrm{~g} / \mathrm{m}^{2}$ for OC and $343 \mathrm{~g} / \mathrm{m}^{2}$ for EC, respectively. The transport fluxes reveal a significant north-south atmospheric transport route. The northwardly and southwardly transport fluxes were $54 \%$ and $46 \%$ for OC, and $43 \%$ and 57\% for EC, respectively (see SI Fig. S17). The northwardly transport mainly occurred during spring and summer and the southwardly transport mostly presented during winter and autumn, respectively, for both OC and EC (see SI Fig. S17).

Open burning of agricultural wastes occurs mainly in spring and summer as shown in SI Fig. S9. To estimate the impact of agricultural waste open burning to the transport flux of OC and EC, we selected measured concentrations of $\mathrm{OC}$ and $\mathrm{EC}$ on those sampling days during spring and summer when backward trajectories from the sampling site never meet fire counts. The selected and seasonal concentration levels of OC and EC are displayed in SI Fig. S18. By comparing with seasonal concentrations, the selected OC and EC values were evidently lower in summer than in spring.

The arithmetical mean, median and geometrical mean of the selected spring/summer concentrations accounted for $89 / 52 \%, 88 / 70 \%$ and $90 / 66 \%$ for respective seasonal OC, and $95 / 52 \%, 83 / 82 \%$ and $95 / 63 \%$ for the respective seasonal EC, respectively. The arithmetical mean, median and geometrical mean of the selected OC and EC concentrations in spring and summer acted as a proxy of the two seasonal concentrations to assess indirectly the transport fluxes of OC and EC contributed by agricultural field burning in the Shandong Peninsula. The contribution of agricultural field burning to $\mathrm{OC}$ and EC transport fluxes was assessed by a ratio expressed as $\left(\mathrm{F}_{\mathrm{a}}-\mathrm{F}_{\mathrm{s}}\right) / \mathrm{F}_{\mathrm{a}}$. In which, $\mathrm{F}_{\mathrm{a}}$ and $\mathrm{F}_{\mathrm{s}}$ are the transport fluxes calculated by seasonal and selected concentration of $\mathrm{OC}$ and $\mathrm{EC}$, respectively. The ratios were shown to be northwardly and southwardly transport fluxes as presented in Fig. 3. The ratios for OC and EC in spring were less than $20 \%$, suggesting a weak influence of open burning of agricultural wastes on the transport fluxes. However, the ratios in summer, in particular for the northwardly transport were obviously higher than that in spring. As seen in Fig. 3, the result indicates that open burning of crop residues in the Shandong Peninsula contributed $53-61 \%$ and $50-56 \%$ of OC and EC northwardly transport in summer, respectively.

\section{Conclusions and recommendations}

In this study, carbonaceous aerosols in $\mathrm{PM}_{2.5}$ samples collected at the $\mathrm{TI}$, China were analyzed to assess the temporal variation of OC and EC concentrations associated with environmental factors. The annual arithmetical means of OC and EC concentrations contributed $8 \%$ and $4 \%$ of $\mathrm{PM}_{2.5}$ mass concentrations, respectively. The seasonal EC concentrations were the highest levels in winter, contributed mainly by the outflow from the northwest source region carried by the East Asian winter monsoon. The peak OC concentrations occurred during spring, attributed largely to biofuel burning in the Shandong Peninsula, and short distance and favorable transport pathway from the peninsula to the TI. Agricultural waste open burning in the Shandong Peninsula was a main contributor to $\mathrm{OC}$ and EC concentrations and northwardly transports in Bohai Rim region in summer.

It is worthwhile to note that the emission from agricultural waste burning in field is much easier to be controlled than that from other

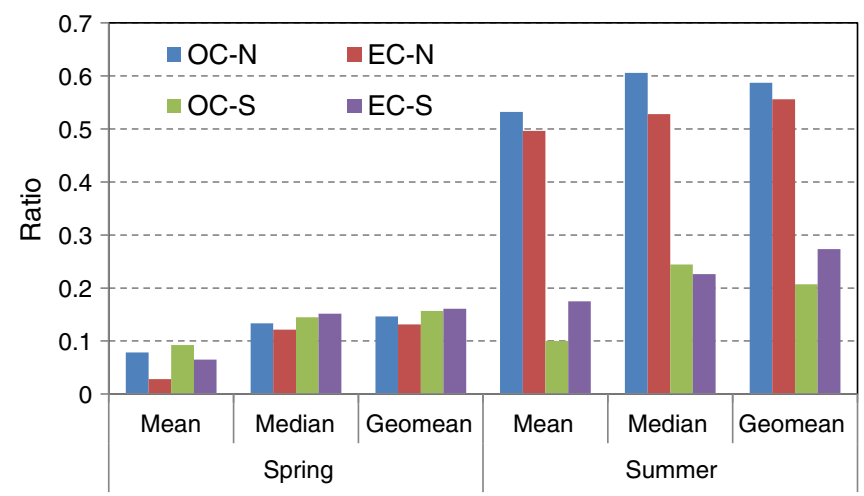

Fig. 3. Ratios of $O C$ and EC transport fluxes contributed by agricultural field burning in spring and summer at Tuoji Island, China. 
sectors, such as industrial, civil and traffic sources. As shown in SI Fig. S19, 72-h back trajectories from the TI in summer passed mainly through areas with sparse fire counts in the peninsula, which contributed about half of northwardly transport of OC and EC in the season as mentioned above. Similarly, 72-h forward trajectories of air masses from areas with dense fire counts in the peninsula also showed mainly northwardly transport (seen SI Fig. S19), which can result in more serious contamination of OC and EC around Bohai Rim region than that estimated at the TI. Based on MODIS images, large-scale flow field charts and environmental monitoring data, Li et al. also estimated that open burning of wheat straw in Shandong in June contributed partly to the degradation of Beijing air quality (Li et al., 2008). According to the estimation, eliminating agricultural field burning in the Shandong Peninsula can reduce at least 38\% (30-48\%) concentration levels and 57\% (53-60\%) of northwardly transport fluxes for OC, and 34\% (18-48\%) and 51\% (47-53\%) for EC in Bohai Rim region in summer, which should attract great concern by the government for environmental and health benefits. Recovery and reuse of agricultural wastes are effective pathways to eliminate the emission, which need to be supported by official policy because of their low income.

\section{Conflict of interest statement}

We declare that we have no financial and personal relationships with other people or organizations that can inappropriately influence our work. There is no professional or other personal interest of any nature or kind in any product, service and/or company that could be construed as influencing the position presented in, or the review of, the manuscript entitled, "Impact of Agricultural Waste Burning in the Shandong Peninsula on Carbonaceous Aerosols in the Bohai Rim, China".

\section{Acknowledgments}

This work was supported by the Promotive Research Foundation for Excellent Young and Middle-aged Scientists of Shandong Province (No. BS2012HZ028), the CAS Strategic Priority Research Program (Nos. XDB05020207, XDB05030303 and XDA11020402), and the Natural Scientific Foundation of China (Nos. 41101495 and 41125014). The authors gratefully acknowledge the National Oceanic and Atmospheric Administration's Air Resources Laboratory for providing the HYSPLIT transport model and the READY website (http://www.arl.noaa.gov/ ready.html).

\section{Appendix A. Supplementary data}

Supplementary data to this article can be found online at http://dx. doi.org/10.1016/j.scitotenv.2014.02.064.

\section{References}

Anenberg SC, Talgo K, Arunachalam S, Dolwick P, Jang C, West JJ. Impacts of global, regional, and sectoral black carbon emission reductions on surface air quality and human mortality. Atmos Chem Phys 2011;11:7253-67.

Cao G, Zhang X, Zheng F. Inventory of black carbon and organic carbon emissions from China. Atmos Environ 2006;40:6516-27.

Cao JJ, Lee SC, Chow JC, Watson JG, Ho KF, Zhang RJ, et al. Spatial and seasonal distributions of carbonaceous aerosols over China. J Geophys Res 2007;112. [D22S11].
Chow JC, Watson JG, Pritchett LC, Pierson WR, Frazier CA, Purcell RG. The DR thermal/optical reflectance carbon analysis system: description, evaluation and applications in U.S. air quality studies. Atmos Environ A 1993;27:1185-201.

Draxler RR, Rolph GD. HYSPLIT (HYbrid Single-Particle Lagrangian Integrated Trajectory) model access via NOAA ARL READY website. NOAA Air Resources LaboratorySilver Spring, MD: NOAA Air Resources Laboratory; 2003 [http://www.arl.noaa.gov/ready/ hysplit4.html].

Fang G-C, Wu Y-S, Chou T-Y, Lee C-Z. Organic carbon and elemental carbon in Asia: a review from 1996 to 2006. J Hazard Mater 2008;150:231-7.

Feng J, Guo Z, Chan CK, Fang M. Properties of organic matter in $\mathrm{PM}_{2.5}$ at Changdao Island, China-a rural site in the transport path of the Asian continental outflow. Atmos Environ 2007;41:1924-35.

Feng J, Guo ZG, Zhang TR, Yao XH, Chan CK, Fang M. Source and formation of secondary particulate matter in $\mathrm{PM}_{2.5}$ in Asian continental outflow. J Geophys Res 2012;117. [D03302].

Hu WW, Hu M, Deng ZQ, Xiao R, Kondo Y, Takegawa N, et al. The characteristics and origins of carbonaceous aerosol at a rural site of PRD in summer of 2006. Atmos Chem Phys 2012;12:1811-22.

Huang C, Chen CH, Li L, Cheng Z, Wang HL, Huang HY, et al. Emission inventory of anthropogenic air pollutants and VOC species in the Yangtze River Delta region, China. Atmos Chem Phys 2011;11:4105-20.

Huang X, Li M, Li J, Song Y. A high-resolution emission inventory of crop burning in fields in China based on MODIS thermal anomalies/fire products. Atmos Environ 2012;50: 9-15.

Jhun J-G, Lee E-J. A new East Asian winter monsoon index and associated characteristics of the winter monsoon. J Clim 2004;17:711-26.

Li L, Wang Y, Zhang Q Li J, Yang X, Jin J. Wheat straw burning and its associated impacts on Beijing air quality. Sci China D Earth Sci 2008;51:403-14.

Lim HJ, Turpin BJ, Russell LM, Bates TS. Organic and elemental carbon measurements during ACE-Asia suggest a longer atmospheric lifetime for elemental carbon. Environ Sci Technol 2003;37:3055-61.

Lim S, Lee M, Lee G, Kim S, Yoon S, Kang K. Ionic and carbonaceous compositions of $\mathrm{PM}_{10}$ $\mathrm{PM}_{2.5}$ and $\mathrm{PM}_{1.0}$ at Gosan $\mathrm{ABC}$ superstation and their ratios as source signature. Atmos Chem Phys 2012;12:2007-24.

Liu Q Yang Z. Quantitative estimation of the impact of climate change on actual evapotranspiration in the Yellow River Basin, China. J Hydrol 2010;395:226-34.

Louis G. MODIS collection 5 active fire product user's guide-version 2.5. University of Maryland: College ParkUniversity of Maryland: College Park; 201361 [March, 31].

Ma JZ, Wang W, Chen Y, Liu HJ, Yan P, Ding GA, et al. The IPAC-NC field campaign: a pollution and oxidization pool in the lower atmosphere over Huabei, China. Atmos Chem Phys 2012;12:3883-908.

Mohsin T, Gough W. Trend analysis of long-term temperature time series in the Greater Toronto Area (GTA). Theor Appl Climatol 2010;101:311-27.

Qin Y, Xie SD. Historical estimation of carbonaceous aerosol emissions from biomass open burning in China for the period 1990-2005. Environ Pollut 2011;159:3316-23.

Qin Y, Xie SD. Spatial and temporal variation of anthropogenic black carbon emissions in China for the period 1980-2009. Atmos Phys 2012;12:4825-41.

Ramanathan V, Carmichael G. Global and regional climate changes due to black carbon. Nat Geosci 2008;1:221-7.

Ramanathan V, Crutzen PJ, Kiehl JT, Rosenfeld D. Aerosols, climate, and the hydrological cycle. Science 2001;294:2119-24.

Singh HB, Brune WH, Crawford JH, Flocke F, Jacob DJ. Chemistry and transport of pollution over the Gulf of Mexico and the Pacific: spring 2006 INTEX-B campaign overview and first results. Atmos Chem Phys 2009;9:2301-18.

Streets DG, Bond TC, Lee T, Jang C. On the future of carbonaceous aerosol emissions. J Geophys Res 2004;109. [D24212].

Xin J, Wang L, Wang Y, Li Z, Wang P. Trends in aerosol optical properties over the Bohai Rim in Northeast China from 2004 to 2010. Atmos Environ 2011;45:6317-25.

Yue S, Pilon P, Phinney B, Cavadias G. The influence of autocorrelation on the ability to detect trend in hydrological series. Hydrol Process 2002;16:1807-29.

Zhang G, Li J, Li X-D, Xu Y, Guo L-L, Tang J-H, et al. Impact of anthropogenic emissions and open biomass burning on regional carbonaceous aerosols in South China. Environ Pollut 2010;158:3392-400.

Zhang Y, Shao M, Lin Y, Luan S, Mao N, Chen W, et al. Emission inventory of carbonaceous pollutants from biomass burning in the Pearl River Delta Region, China. Atmos Environ 2012;76:189-99.

Zhao B, Wang P, Ma JZ, Zhu S, Pozzer A, Li W. A high-resolution emission inventory of primary pollutants for the Huabei region, China. Atmos Chem Phys 2012;12:481-501. 